\title{
Strengthening Gastric Cancer Therapy by Trastuzumab-Conjugated Nanoparticles with Simultaneous Encapsulation of Anti- MiR-21 and 5-Fluorouridine
}

\author{
Nan Hua Jun Feng Yin ${ }^{b}$ Ze Jic Yidong Hong ${ }^{a}$ Puyuan Wu ${ }^{d}$ Baoxiang Bian \\ Ziyan Song $^{\mathrm{a}}$ Rutian $\mathrm{Li}^{\mathrm{d}}$ Qin Liu ${ }^{\mathrm{d}}$ Fenglei $\mathrm{Wu}^{\mathrm{a}}$ \\ aDepartment of Oncology, Affiliated Lianyungang Hospital of Xuzhou Medical University, Lianyungang, \\ bDepartment of General Surgery, The Affiliated Hospital of Yangzhou University, Yangzhou University, \\ 'Deparment of Respiratory Medicine, Suzhou Kowloon Hospital, Shanghai Jiaotong University School \\ of Medicine, Suzhou, dThe Comprehensive Cancer Centre of Drum Tower Hospital, Medical School of \\ Nanjing University, Clinical Cancer Institute of Nanjing University, Nanjing, P.R. China
}

\section{Key Words}

Microrna • Gastric cancer • HER2 (human epidermal growth factor receptor 2) • Trastuzumab - Nanoparticles - PTEN (phosphatase and tensin homolog)

\begin{abstract}
Background/Aims: MicroRNA-21 is an oncogenic miR (oncomiR) frequently elevated in gastric cancer (GC). Overexpression of miR-21 decreases the sensitivity of GC cells to 5 -fluorouridine (5-Fu) and trastuzumab, a humanized monoclonal antibody targeting human epidermal growth factor receptor 2 (HER2). Receptor-mediated endocytosis plays a crucial role in the delivery of biotherapeutics including anti-miRNA oligonucleotides (AMOs). This study is a continuation of earlier findings involving poly( $\varepsilon$-caprolactone) $(\mathrm{PCL})$-poly (ethylene glycol) (PEG) nanoparticles (PEG-PCL NPs), which were coated with trastuzumab to target GC with HER2 receptor over-expression using anti-miRNA-21 (AMO-21) and 5-Fu. Methods: HER-PEG-PCL NPs were prepared by one-step carbodiimide coupling using 1-ethyl-3-(3dimethylaminopropyl) carbodiimide hydrochloride (EDAC) and Sulfo-NHS in aqueous phase. Covalent coupling of amino groups at the surface of PEG-PCL with the carboxyl groups of trastuzumab was analyzed by X-ray photoelectron spectroscopy (XPS). AMO-21/5-Fu NPs were formulated by a double-emulsion solvent evaporation technique. The cell line specificity, cellular uptake and AMO-21 delivery were investigated through the rhodamine-B-labeled 6-carboxyfluorescein (FAM)-AMO-21-PEG-PCL NPs coated with or without the antibody in both Her2-positive (NUGC4) and negative GC cells (SGC7901) visualized by fluorescence microscopy. The cytotoxicity of the HER-PEG-PCL NPs encapsulating AMO-21 was evaluated by MTT and apoptosis. Real-time reverse-transcription polymerase chain reaction (RT-PCR) N. Hu, J. Yin and Z. Ji contributed equally to this work.
\end{abstract}


was used to examine miR-21 and phosphatase and tensin homolog (PTEN) and Sprouty2 expression in GC cell lines. The antitumor effects of AMO-21/5-Fu NPs were compared with other groups in xenograft gastric cancer mice. Results: The antibody conjugates significantly enhanced the cellular uptake of NPs. The AMO-21/5-Fu NPs effectively suppressed the target miRNA expression in GC cells, which further up-regulated PTEN and Sprouty2. As a result, the sensitivity of HER2-expressing gastric cancer to trastuzumab and 5-Fu were enhanced both in vitro and in vivo. The approach enhanced the targeting by trastuzumab as well as antibodydependent cellular cytotoxicity (ADCC) of immune effector cells Conclusions: Taken together, the results provide insight into the biological and clinical potential of targeted AMO-21 and 5-Fu co-delivery using modified trastuzumab for GC treatment.

\section{Introduction}

C 2017 The Author(s)

Published by S. Karger AG, Basel

Gastric cancer (GC) ranks fourth among all cancers in worldwide incidence. It ranks second in cancer-related deaths reported in China [1]. Most patients are diagnosed with surgically advanced or metastatic disease [2] that require chemotherapy. The most commonly used chemotherapeutic agent for the treatment of GC is 5-Fu, but the response rate of this single agent chemotherapy is only about $11 \%$ [3]. Approximately $7 \%$ to $34 \%$ of gastric cancers are characterized by poor prognosis associated with amplification HER2 [4-6]. Treatment with a combination of trastuzumab (a humanized monoclonal antibody against HER2) and 5-Fu is indicated for HER2-positive advanced GC. Despite a significant survival advantage with the combination treatment, $12 \%$ of all HER2-positive GC cases show cancer progression [7].

MicroRNAs (miRs) are well known for suppression of translation via RNA-induced silencing complex (RISC) [8]. Changes in miRNA expression profile is correlated with tumor pathogenesis, cancer progression, and drug resistance [9]. Therefore, AMOs facilitate tumor therapy by abrogating the expression of specific miRs [10-13]. Down-regulation of miR-21, a gastric oncomiR, not only enhances the sensitivity of HER2-positive GC in vitro, in response to trastuzumab by regulating the miR-21 targeting gene PTEN [14], but also the sensitvity of 5 -Fu by regulating the miR-21 targeting gene Sprouty2 [15]. Thus, targeted AMO-21 delivery improves the efficacy of trastuzumab and 5-Fu simultaneously.

However, AMO is sensitive to nucleases. It is hydrophilic with poor membrane permeability. The stability and efficiency of AMO therapy is increased by treatment with 2'-0-methyl or 2'-0-methoxyethyl agents [16]. The modifications may reduce the specificity and affinity for the target miRNAs [17], interfering with the efficient delivery of AMOs into cells. Therefore, enhancing the delivery of AMO using effective carrier vectors or Lipofectamine 2000 has been shown to be effective in proof-of-concept experimental studies. Nevertheless, viral vectors are potentially oncogenic, triggering immune response, inducing viral mutations and possess limited loading capacity [18]. Lipofectamine 2000 is potentially cytotoxic, non-specific for tissues, and is sensitive to serum proteins [18]. Safe and effective nonviral delivery systems are needed for clinically viable cancer treatment. Polymeric nanoparticle-based delivery is a promising strategy with high transfection efficiency. Polymeric nanoparticles are easily modified and functionally enhanced, and delivered safely without any toxicity [19]. Therefore, the design of a targeted nanoparticle system could overcomes the disadvantages of AMO effectively.

Nanodelivery systems have been shown to overcome the challenges posed by AMOs in therapeutic drug delivery in cancer using miRNA interference $[20,21]$. The challenges of effective gene silencing relate to active recognition of target cells, without affecting normal cells [22]. Complexation of NPs with target-specific ligands or antibodies enhances therapeutic efficacy by facilitating targeted delivery to cancer cells [23, 24]. Based on the previous studies, trastuzumab was conjugated with poly(ethyleneglycol) (PEG) and poly( $\varepsilon$ caprolactone) (PCL) copolymers [25], using PEG as the linker molecule (HER-PEG-PCL). Receptor mediated targeting of GC cells was accomplished by overexpressing HER2, using 


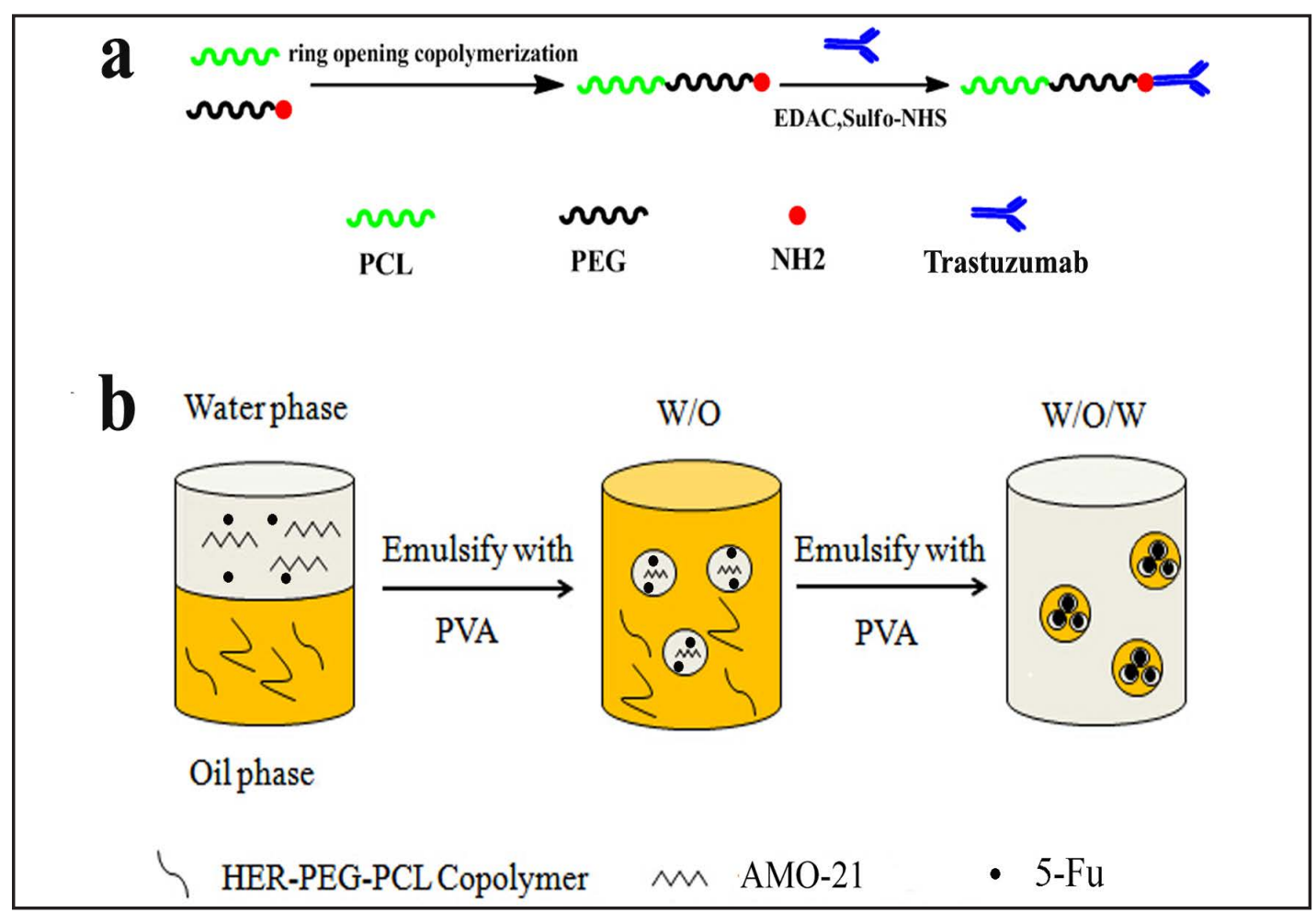

Fig. 1. (a) Schematic illustrating the fabrication of trastuzumab-conjugated PEG-PCL NPs: the NPs comprise a PCL core, a hydrophilic and stealth PEG shell on the surface of the core and a trastuzumab ligand coating. (b) The scheme of AMO-21-HER-PEG-PCL NPs preparation (NPs, nanoparticles; AMO-21, anti-miR-21 oligonucleotide).

precision engineering of nanoparticles of biodegradable copolymers to quantitatively control AMO-21 and 5-Fu delivery (Fig. 1a). The approach enhances the targeting by trastuzumab as well as ADCC of immune effector cells and the sensitivity of 5-Fu. The surface ligand density of molecules has been contorlled by using copolymers and trastuzumab in therapeutically effective ratios. The AMO-21 and 5-Fu were co-delivered targetedly by HER-PEG-PCL (AMO21/5-Fu TNPs) to GC cells overexpressing NUGC4 and not SGC7901. The AMO-21-loaded PEG-PCL nanoparticles (AMO-21/5-Fu NPs) that failed to target HER2, and Lipofectamine 2000 were used as controls. It was hypothesized that trastuzumab combined with AMO21 and 5-Fu was a promising therapeutic strategy for cancer. Enhanced trastuzumab and 5-Fu cytotoxicity in GC are mediated by the antagonism of target miR-21 against increased expression of PTEN and Sprouty2 respectively. Thus, multifunctional nanoparticles may represent a generalized approach for the treatment of GC.

\section{Materials and Methods}

\section{Synthesis of PEG-PCL and HER-PEG-PCL copolymers}

The PEG-PCL copolymers were prepared via ring opening copolymerization as described previously [25]. A single-step carbodiimide coupling with EDAc and Sulfo-NHS in aqueous phase was used to develop conjugates of trastuzumab [23]. Briefly, the stock solution $(1 \mathrm{mg} / \mathrm{mL})$ was prepared by diluting trastuzumab in borate buffer (pH 8.4). Dry PEG-PCL NPs was incubated with trastuzumab in borate buffer and supplemented with EDAc and Sulfo-NHS. The free primary amino groups on the NPs surface were conjugated with the carboxylic groups on the antibodies. After incubation overnight at room temperature under gentle end-to-end mixing, followed by centrifugation, the NPs were obtained. NPs were washed twice with borate buffer. The pellets were treated with ultrapure water for further analysis. The supernatant was 
scanned for antibody concentration at $595 \mathrm{~nm}$ using an ELISA plate Reader (Synergy HT, BioTek Instruments Inc., Winooski, Vermont). The antibody levels on the NPs surface were determined by subtracting the levels in the supernatant from the original concentration.

\section{Preparation of AMO-21/5-Fu co-loaded nanoparticles}

The AMO-21(GenePharm, Shanghai, China) and 5-Fu containing PEG-PCL or HER-PEG-PCL nanoparticles were developed by a double-emulsion solvent evaporation technique according to published methods [26]. In brief, AMO-21 combined with spermidine in a 10:1 molar ratio of polyamine nitrogen to polynucleotide phosphate (N/P ratio) and 5-Fu were dissolved in RNAse- and DNAse-free phosphate buffered saline (PBS) (0.01 M, pH 7.4). Polyamine complexes containing AMO-21 and 5-Fu were developed at room temperature for $15 \mathrm{~min}$ on a rotary shaker. This aqueous solution was added dropwise to a polymer solution of copolymer $(3 \mathrm{mg})$ dissolved in dichloromethane $(100 \mathrm{~mL})$. This was done in the presence of sonication and stirring (XL2000, Misonix, Farmingdale, New York, USA) for 30 seconds to yield a water-in-oil (W/0) emulsion. This mixture was then added dropwise to $5 \%$ polyvinyl alcohol (PVA) and sonicated to form the water-in-oil-in-water (W/O/W) emulsion. This final emulsion was transferred into a beaker containing aqueous $0.3 \%$ (v/v) PVA (Fig. 1b) and stirred for 3 hours to allow evaporation of dichloromethane at room temperature in a fume cupboard. The resulting solution was filtered through a membrane $(1 \mu \mathrm{m}$ pore size, GE Whatman-Xinhua, Shanghai, China) to remove copolymer aggregates. The NP suspensions were freeze dried with Pluronic $®$ F68 $(40 \mathrm{mg} / \mathrm{mL})$ for further use [27]. The supernatant was used to measure the antibody concentrations by ELISA as described previously [28].

\section{Surface chemistry}

The presence of trastuzumab on NPs surface was determined by XPS. The NPs surface was further analyzed in terms of the specific binding energy $(\mathrm{eV})$ of the elements. The $\mathrm{eV}$ was recorded from 0 to 1000 $\mathrm{eV}$, with pass energy of $80 \mathrm{eV}$ under fixed transmission. Nitrogen was analyzed under fine mode with $0.5 \mathrm{eV}$. The data were processed using specific XPS software.

\section{Size, surface charge, encapsulation and drug loading measurement efficiency}

The size, dispersity, zeta potential, and morphology of NPs were determined. Dynamic light scattering (DLS) (Brookhaven Instruments Corporation, USA) was employed to measure the hydrodynamic size and polydispersity. Zeta potential was measured using Zetaplus (Brookhaven Instruments Corporation, USA). The samples were stored at $37^{\circ} \mathrm{C}$ in PBS. The morphology of NPs was analyzed using transmission electron microscopy (TEM, JEM-100S, JEOL, Japan). A single drop of diluted NP suspension on a copper grid covered with nitrocellulose membrane was air-dried at room temperature and negatively stained with phosphotungstic sodium solution (1\% w/v). Encapsulation efficiency (EE) and drug loading content (DLC) of AMO-21 were determined [26]. In brief, AMO-21/5-Fu NPs (15 mg) were dissolved in dichloromethane $(0.5 \mathrm{~mL})$ at room temperature for $30 \mathrm{~min}$, followed by extraction of AMO-21 from the organic phase using twice the volume of TE buffer (10 mM Tris e HCl, $1 \mathrm{mM}$ EDTA , pH 7.4). After vortexing vigorously, the mixture was centrifuged at $12,000 \mathrm{rpm}$ and $4 \stackrel{\circ}{ } \mathrm{C}$ for $10 \mathrm{~min}$. The AM0-21 level was analyzed using the QuantiT $^{\mathrm{TM}}$, PicoGreen ${ }^{\mathrm{TM}}$ assay according the manufacturer's instructions (Invitrogen, USA).

The EE and DLC of 5-Fu were analyzed by High Performance Liquid Chromatography (HPLC) system (Agilent 1200 HPLC system, Agilent Technologies, Palo Alto, USA) as previously described. Chromatographic separation was achieved using a C18 reversed phase column $(250 \mathrm{~mm} \times 4.6 \mathrm{~mm}, 5 \mu \mathrm{M}$, ZORBAX Eclipse XDB-C18, Agilent Technologies, Palo Alto, USA) as the stationary phase. The mobile phase for 5-FU included sterile degassed methanol:water $(10: 90 \mathrm{v} / \mathrm{v})$ with an injection volume of $20 \mu \mathrm{L}$ and a flow rate of $0.8 \mathrm{~mL} /$ min. This was held in an isocratic mode for $6 \mathrm{~min}$ at a wavelength of $265 \mathrm{~nm}$ using a UV detector. The retention time of 5-Fu was approximately $2.1 \mathrm{~min}$.

The DLC and EE were calculated by the following equations:

DLC\% $=$ (Weight of the drug nanoparticles/Weight of the drug loaded nanoparticles $) \times 100 \%$

$\mathrm{EE} \%=$ (Weight of the drug nanoparticles/Weight of the feeding drug) $\times 100 \%$

AMO-21 and 5-Fu release from TNPs in vitro

The release of AM0-21/5-Fu NPs was determined by dissolving 25mg NPs in RNAse- and DNAse-free PBS (0.01 M, pH 7.4) and transferred into a dialysis bag (MWCO $3500 \mathrm{Da}$ ). The dialysis bag was immerged in $5 \mathrm{~mL}$ release medium under gentle agitation at $37^{\circ} \mathrm{C}$ for 100 hours. At predetermined time points, the 


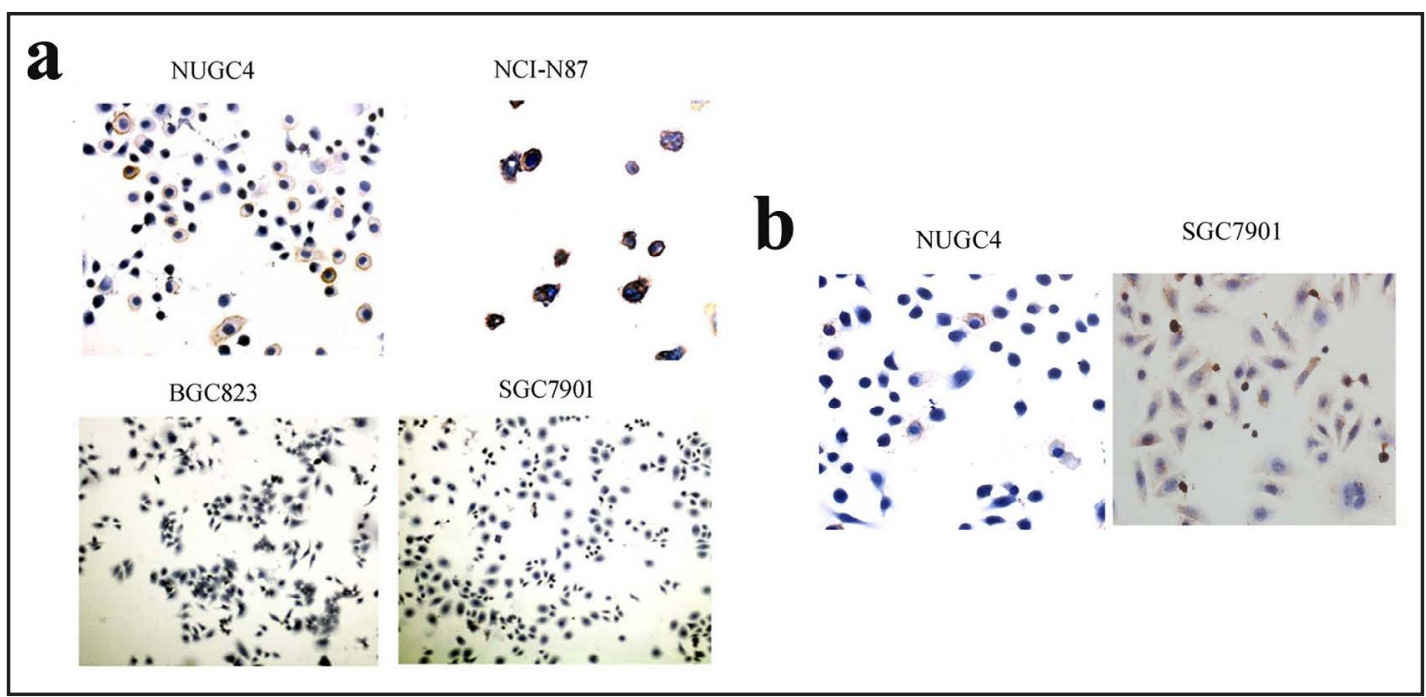

Fig. 2. Detection of HER2 expression. (a) Immunohistochemica analysis of HER2 expression in NUGC4, NCI-N87, BGC823 and SGC7901 cells. (b) Immunohistochemica analysis of Sprouty2 expression in NUGC4 and SGC7901 cells. (HER2, human epidermal growth factor receptor 2).

release medium was replaced by an equivalent release medium. The AMO-21 concentration was analyzed using QuantiT ${ }^{\mathrm{TM}}$, PicoGreen $^{\mathrm{TM}}$ assay and the 5-Fu was determined by HPLC analysis.

\section{Cell culture}

NUGC4, NCI-N87, SGC7901 and BGC823 were supplied by American Type Culture Collection (ATCC). HER2 expression level in the cells was evaluated by western blot and immunohistochemistry as previously described [29]. HER2 was expressed positively in NCI-N87 and NUGC4 cells,

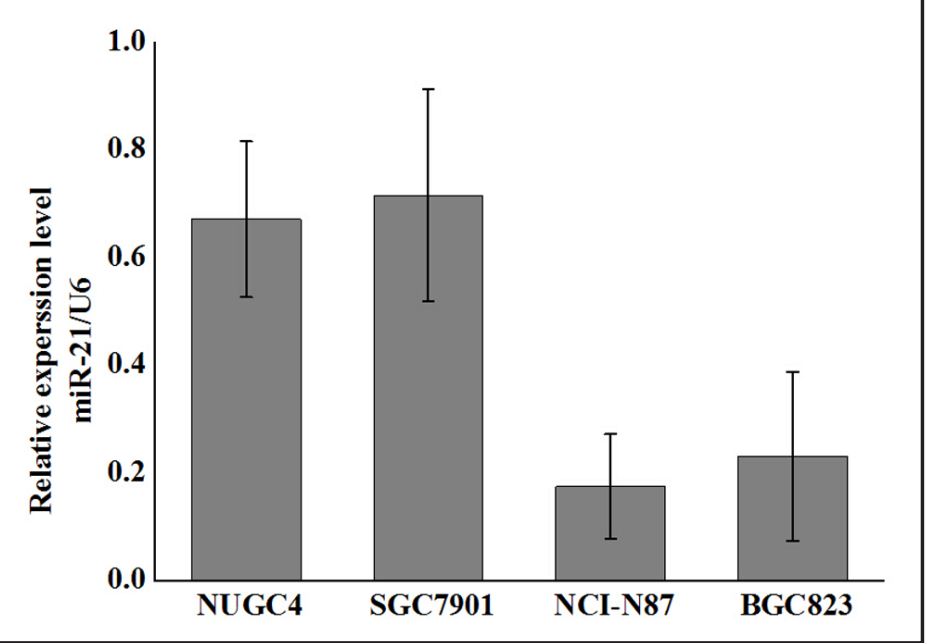

Fig. 3. Expression of miR-21 in NUGC4, NCI-N87, BGC823 and SGC7901 cells was detected by RT-qPCR. (RT-qPCR, real-time reversetranscription polymerase chain reaction). and negatively in SGC7901 and BGC823 (Fig. 2a), consistent with previous studies [14, 30]. The expression level of Sprouty2 was found lower in NUGC4 GC cells while higher in SGC7901 (Fig. 2b). The miR-21 expression in the cells showing HER2-positive expression was determined by RT-PCR [14]. The expression of miR-21 was higher in NUGC4 SGC7901 than in NCI-N87 BGC823 cells (Fig. 3), which were therefore, selected for further study. All cells were cultured in RPMI 1640 medium, supplemented with $10 \%$ fetal bovine serum and incubated at $37^{\circ} \mathrm{C}$ at $5 \%$ CO2 and $95 \%$ humidity.

\section{Cellular uptake by fluorescence microscopy}

Rhodamine B-labeled particles were reacted with hydroxyl group in HER-PEG-PCL and PEG-PCL copolymers as previously described [31]. This Rhodamine B labeled NPs were then loaded with FAM-labeled AMO-21 (FAM-AMO-21) and the fluorescent signals Rhodamine-B (red) and FAM (green) respectively tracked the location of NPs and AMO-21 in NUGC4 and SGC7901 cells. Cells were loaded in 6-well plates at a density of $2 \times 10^{5}$ cells/well and incubated overnight. An additional incubation for 2 hours was performed 


\section{Cellular Physiology and Biochemistry \\ Cell Physiol Biochem 2017;44:2158-2173 \\ \begin{tabular}{l|l}
\hline DOI: 10.1159/000485955 & (C) 2017 The Author(s). Published by S. Karger AG, Basel
\end{tabular} \\ Published online: December 12, 2017 www.karger.com/cpb}

Hu et al.: Gastric Cancer Therapy

using a fixed concentration of FAM-AMO-21-loaded Rhodamine B-labeled HER-PEG-PCL and PEG-PCL NPs. The cells were washed three times with PBS, and fixed with $4 \%$ paraformaldehyde (PFA) for 30 min at room temperature. Following another round of washing the media were replaced with fresh culture media. The fluorescence was determined using an Olympus LX71 epifluorescence microscope (Olympus, Tokyo, Japan). For quantification, the color change in the PEG-PCL and HER-PEG-PCL groups was detected by the naked eye and analyzed using image analysis software (ImageJ). The integrated optical density (IOD) was used to quantify the fluorescence. The IOD of Rhodamine B and FAM were evaluated by performing tests under identical experimental conditions, in triplicate.

\section{In vitro cytotoxicity of AMO-21/5-Fu TNPs}

The cytotoxic potential of NPs was evaluated by MTT assay as previously described [32]. NUGC4 and SGC7901 cells were incubated overnight in 96-well culture plates at a density of 4000 cells/well, and treated differently to analyze cell proliferation. The different groups were as follows: saline control, blank NPs, blank TNPs (equal trastuzumab concentration), trastuzumab $(51 \mu \mathrm{g} / \mathrm{mL}), 5-\mathrm{Fu}(5 \mu \mathrm{g} / \mathrm{mL}), 5$-Fu-TNPs (equal 5-Fu and trastuzumab concentration), trastuzumab + 5-Fu, AMO-21 (100nmol/L) /5-Fu-NPs(equal 5-Fu and trastuzumab concentration), AMO-21(100nmol/L)/5-Fu-TNPs(equal 5-Fu and trastuzumab concentration). Cell proliferation was examined at an absorbance of $570 \mathrm{~nm}$ every 24 hours for another 4 days.

\section{In vivo antitumor effect of AMO-TNPS}

BALB/c nude mice (male, 4-5 weeks old) were implanted subcutaneously into the right posterior flanks with $0.1 \mathrm{~mL}$ of cell suspension containing $5 \times 10^{6}$ NUGC4 cells. The tumor volume was calculated using the formula $\mathrm{W} \times \mathrm{L}^{2} / 2$, where $\mathrm{W}$ is the widest diameter, and $\mathrm{L}$ is the longest diameter. When $80 \%$ of the tumors reached a volume of $100 \mathrm{~mm}^{3}$, mice were randomly grouped into treatment cohorts, each of which contained 5 mice. Tumor volumes were calculated using the formula: $\left(\mathrm{mm}^{3}\right)=\left(\mathrm{L} \times \mathrm{W}^{2}\right) \times 0.5$. The tumor volume variation was measured in tumor-bearing mice that were treated intravenously with saline control (2 times/week $\times 3$ weeks), NPs, TNPs, trastuzumab (40 mg/kg, 2 times/week $\times 3$ weeks), 5 -Fu + trastuzumab (2 times/week $\times 3$ weeks), AMO-21/5-Fu-TNPs ( $40 \mathrm{mg} / \mathrm{kg}$ trastuzumab eq, 2 times/week $\times$ 3 weeks). The tumors were measured every 3 days until 21 days after treatment. Relative tumor volumes were calculated using the following equation, to reduce the impact of differences in initial tumor volume after grouping:

relative tumor volume $=(\mathrm{V} / \mathrm{V} 0) \times 100 \%$

V is the absolute tumor volume, and V0 was the average tumor volume of the group on Day 1.

Real-time reverse-transcription polymerase chain reaction (RT-PCR)

Saline controls of NUGC4 cells were prepared. The cells were also treated with AMO formulations (free AMO-21, AMO-21-NPs, AMO-21/5-Fu-NPs, AMO-21-Lipofectamine 2000, AMO-21/5-Fu-NPs, AMO-21/5Fu-TNPs) and incubated for an additional 2 days. The total RNA was extracted from the cells using an RNA isolation kit (Tian Gen) as per manufacturer's protocol and stored at $-70^{\circ} \mathrm{C}$ for the use of RT-PCR. The mRNA transcripts were measured with reference to RUN6B, using a SYBR Green qRT-PCR miRNA Detection Kit (TianGen, Bejing, China) and SYBR Green I according to the manufacturer's protocols [33]. SYBR Green qRTPCR was performed to measure mRNA expression levels of PTEN and Sprouty2. Beta-actin (ACTB) was used as an internal control $[34,35]$. All of the primers are listed in Table 1 . The results were analyzed using the $2^{(-\Delta C T)}$ comparative method [36]. All experiments were carried out in triplicate.

\section{Statistical analysis}

All the experiments were performed in triplicate. Continuous variables were expressed as the mean \pm SD. A Student's t-test was used to compare the differences between groups. A $P$ value that was less than 0.05 indicated statistical significance. 


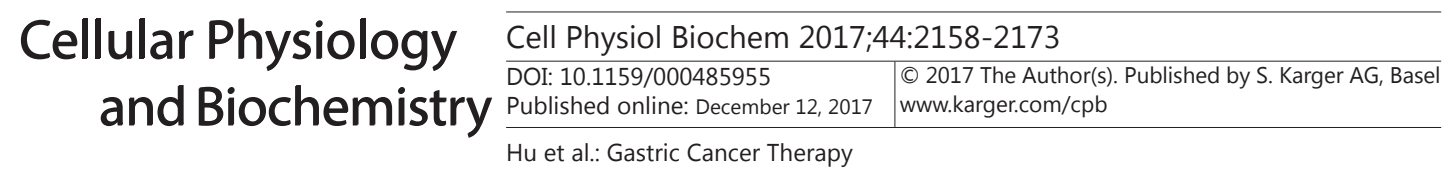

\section{Results}

Preparation of HER-PEG-PCL copolymer

A single-step carbodiimide technique was employed to synthesize HER-PEG-PCL copolymers. The method was based on the PEG-PCL synthesized as described in the first part of Materials and Methods (Synthesis of PEG-PCL and HER-PEG-PCL copolymers). Activation of carboxyl groups on the antibody molecules was followed by reaction with the primary amino groups on the PEG-PCL chains. The resulting amide bonds link the antibodies on the NPs surface. The antibody conjugation of NPs was confirmed by analyzing their surface chemistry using XPS to identify the changes in nitrogen signal according to the specific binding energy. Trastuzumab containing 1726 nitrogen atoms emits stronger signals than the amino groups in the PEG-PCL molecules. Distinct signal peaks emitted from nitrogen ( $\mathrm{N}$ 1s) suggests antibody conjugation in the polymeric matrix cores

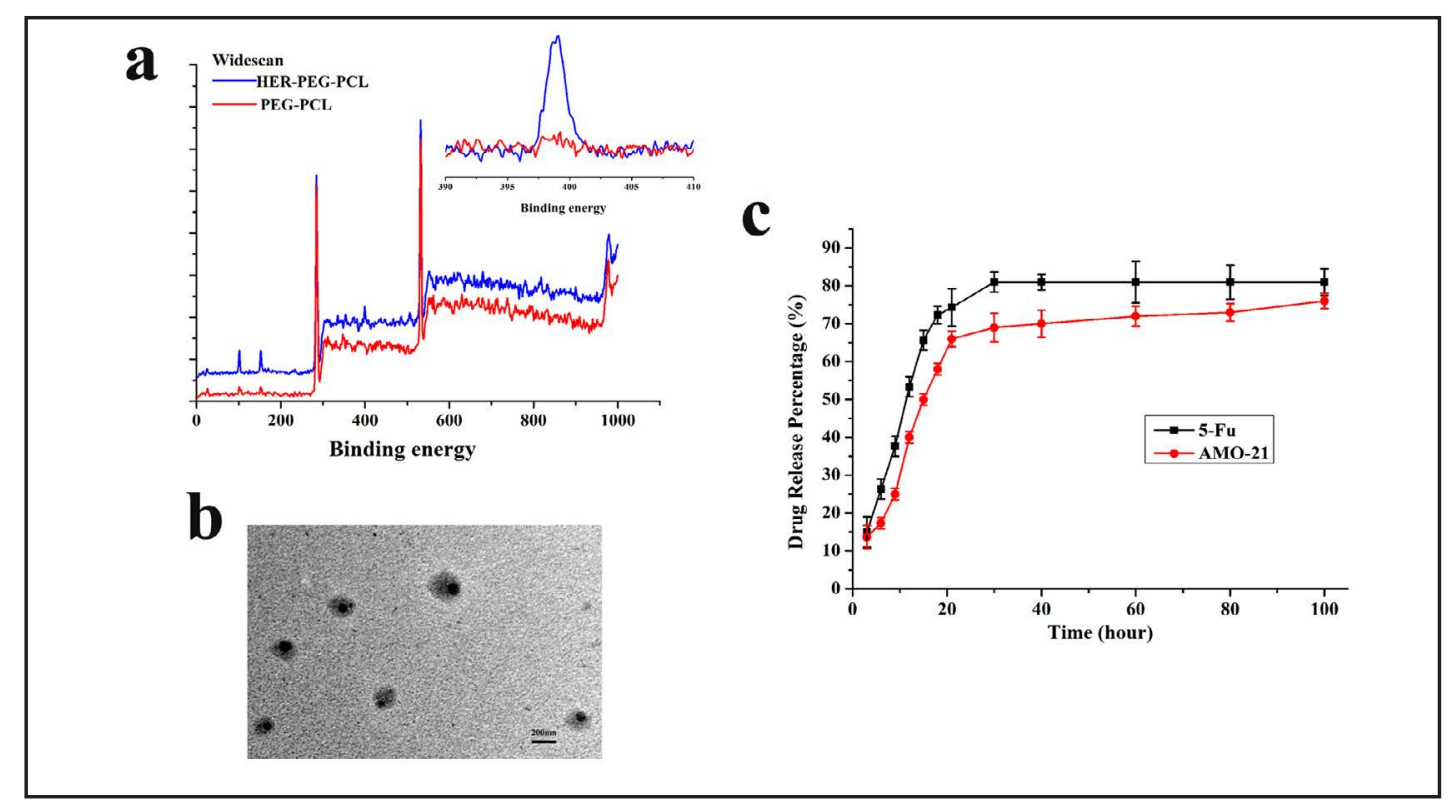

Fig. 4. Characterization of AMO-21-HER-PEG-PCL. (a) Representative XPS spectrum and N 1s peak (the inset) of the HER-PEG-PCL nanoparticles before (lower curve) and after trastuzumab conjugation (upper curve). (b) Morphology of AMO-21-HER-PEG-PCL by TEM. Scale bar represents $200 \mathrm{~nm}$. (c) The in vitro release of AMO-21 and 5-Fu. The data are presented as mean \pm SD. XPS, X-ray photoelectron spectroscopy, AMO-21, anti-miR-21 oligonucleotide; TEM, transmission electron microscope; NPs, nanoparticles; DLS, Dynamic light scattering).
Table 1. Oligonucleotide and primer sed for qRT-PCR analysis

\begin{tabular}{|c|c|}
\hline \multicolumn{2}{|c|}{ Oligonucleotide sequences for miRNA modulation } \\
\hline AMO-21 & TCATGATCA GACTGATAAGCTA \\
\hline \multicolumn{2}{|c|}{ Primers used for qPCR } \\
\hline miR-21_forward & ACACTCCAGCTGGGTAGCTTATCAGACTGA \\
\hline miR-21_reverse & TGGTGTCGTGGAGTCG \\
\hline PTEN_forward & ССТTCTCCATCTCCTGTGTAATCAA \\
\hline PTEN_reverse & GTTGACTGATGTAGGTACTAACAGCAT \\
\hline Sprouty2_forward & ATAATCCGAGTGCAGCCTAAATC \\
\hline Sprouty2_reverse & CGCAGTCCTCACAC CTGTAG \\
\hline U6_forward & CTCGCTTCGGCAGCACA \\
\hline U6_reverse & AACGCTTCACGAATTTGCGT \\
\hline GAPDH_forward & AGCCACATCGCTCAGACAC \\
\hline GAPDH_reverse & GCCCAATACGACCAAATCC \\
\hline
\end{tabular}

(1)

(1)
Oligonucleotide sequences for miRNA modulation 
Table 2. Trastuzumab content of the HER-PEG-PCL nanoparticles of various PEG-PCL amounts used in the nanoprecipitation process. a The SD value was for the mean trastuzumab content $(\% \mathrm{w} / \mathrm{w})$ obtained from the three measurements

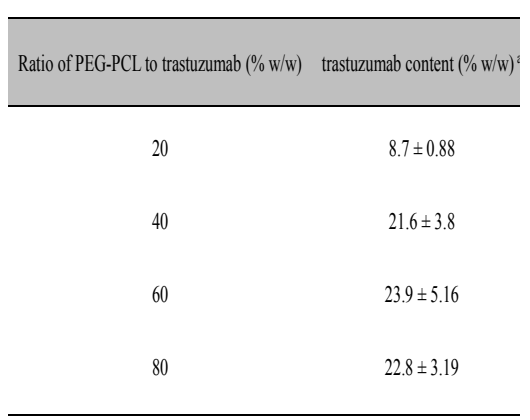

although the non-conjugated NPs also present lower signals associated with nitrogen in the amino groups on the surface. Therefore, the results validate successful conjugation of antibody molecules with the polymer matrix ( Fig. 4a).

\section{Ligand surface density}

The relationship between antibody conjugates on the NPs surface with the PEG-PCL-totrastuzumab ratio was investigated as described priviously [37]. A series of weight ratios (w/w) of PEG-PCL/trastuzumab 20\%, 40\%,60\% and 80\% were used to prepare HER-PEGPCL copolymers. The final levels of trastuzumab conjugated to the NPs surface were: 0.087 , $0.216,0.239$, and $0.228 \mathrm{mg}$ per $\mathrm{mg}$ of NPs after subtracting the background levels using $0 \%$ NPs as control (Table 2). Therefore, $40 \%$ weight ratio (w/w) of PEG-PCL/trastuzumab was selected to synthesize HER-PEG-PCL copolymers for all subsequent experiments.

\section{Preparation and characterization of AMO-21/5-Fu-loaded nanoparticles}

AM0-21-NPs, AMO-21/5-Fu-NPs, AMO-21-TNPs, 5-Fu-TNPs and AMO-21/5-Fu-TNPs were synthesized using a double-emulsion solvent evaporation technique as described earlier. NPs devoid of drug served as controls (NPs control). The average NPs ranged from 186.3 to $233.3 \mathrm{~nm}$ in size, which facilitated the enrichment of NPs in the tumor tissue by increasing the permeability and retention (EPR) [38]. The zeta potentials were negative, ranging from $-9.11 \mathrm{mV}$ to $-13.13 \mathrm{mV}$, and the polydispersity ranged from 0.142 to 0.262 (Table 3). TEM (Fig. 4b) images revealed that AMO-21/5-Fu-TNPs were spherical, measuring approximately 200 $\mathrm{nm}$ in average diameter. The DLCs of AMO-21 in AMO-21-NPs, AMO-21-TNPs, AMO-21/5-FuNPs and AMO-21/5-Fu-TNPs were $0.39 \pm 0.032 \%, 0.38 \pm 0.043 \% 0.36 \pm 0.017 \%$ and 0.34 $\pm 0.042 \%$, respectively. And the DLCs of 5 -Fu in 5-Fu-TNPs, AMO-21/5-Fu-NPs and AMO$21 / 5$-Fu-TNPs were $2.46 \pm 0.012 \%, 2.39 \pm 0.042 \%$ and $2.36 \pm 0.032 \%$, respectively. The EE of AMO-21 in AMO-21-NPs, AMO-21-TNPs, AMO-21/5-Fu-NPs and AMO-21/5-Fu-TNPs were $55.32 \pm 3.3 \%, 54.37 \pm 4.2 \%, 52.27 \pm 3.2 \%$ and $50 \pm 2.9 \%$. The EE of 5 -Fu in 5 -Fu-TNPs, AMO$21 / 5$-Fu-NPs and AMO-21/5-Fu-TNPs were $55 \% \pm 3.2 \%, 52.27 \pm 3.2 \%$ and $55 \pm 3.2 \%$. The trastuzumab content of AMO-21-TNP, 5-Fu-TNP and AMO-21/5-Fu-TNPs were 21.18 2.23 


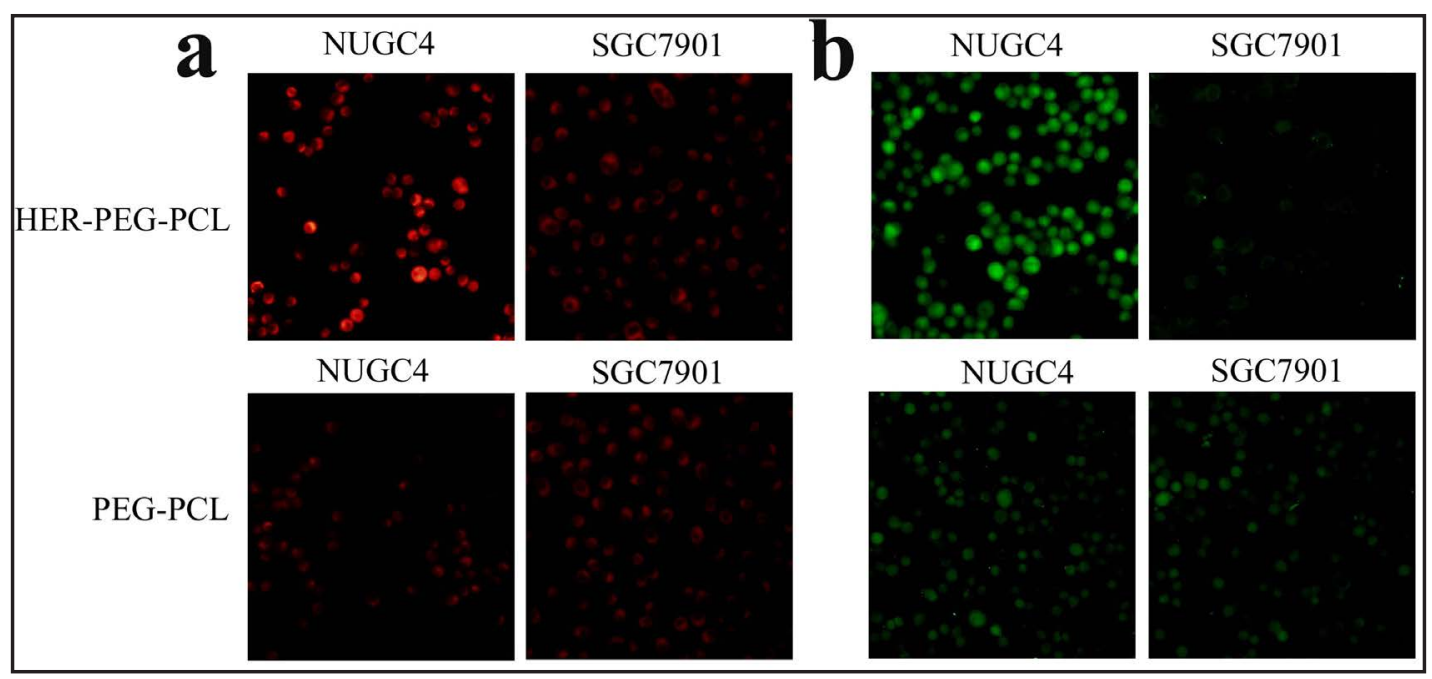

Fig. 5. Fluorescence images of AMO-21-PEG-PCL and AMO-21-HER-PEG-PCL NPs in NUGC4 cells and SGC7901 cells (a) The NPs labeled with the fluorescent rhodamine-B (red) was detected for the celluar uptake (b) The transfection cells were obsreved by AM0-21 labeled with FAM (green). Scale bar: $100 \mu \mathrm{m}$ (NPs, nanoparticles; AMO-21, anti-miR-21 oligonucleotide).

$\%, 24.88 \pm 1.23 \%$ and $23.87 \pm 2.17 \%$, respectively. (summarized in Table. 3). This AMO-21/5-Fu-TNPs formulation yielded a trastuzumab-to 5-FU-toAMO-21 mass ratio of $70.2: 6.9: 1$.

In vitro release and Cellular uptake

The in vitro release profiles of 5-Fu and AMO-21 from TNPs were investigated. $5-\mathrm{Fu}$ presented a burst release from TNPs in the first 20 hours, with nearly $75 \%$ drug released from the carriers. After that, a steady sustained release was observed during the following 100 hours. The release speed of AMO-21 was similar to $5-\mathrm{Fu}$, with nearly $65 \%$ in the first 24 hours (Fig. 4c).

The cellular uptake of HER-PEGPCL nanoparticles based on HER2 expression was investigated. The rhodamine-labeled FAM-AMO-21TNPs and FAM-AMO-21-NPs were used to track the position of nanoparticles and AMO-21. As shown in Fig. 5a, b, HER2-overexpressing NUGC4 cells were used as a positive control to compare the SGC7901 cells with negative HER2 expression. In SGC7901 cells, the IOD of Rhodamine $B$ and FAM did not differ significantly between groups (PEG-PCL, HER-PEG-PCL) $(P>0.05)$. However, the IOD of Rhodamine B and FAM in the HER-PEG-PCL group were significantly higher than the PEG-PCL group in NUGC4 cells $(\mathrm{P}<0.001)$ (Table 4). Moreover, the IOD of Rhodamine B and FAM in the PEG-PCL group indicated similar cellular uptake in both NUGC4 and SGC7901 GC cells (P > 0.05) (Table 5). The fluorescence intensity of PEG-
Table 4. Integrated optical density (IOD) of RhodanminB-PEG-PCL, Rhodanmin-B-HER-PEG -PCL NPs, FAMAMO-21-PEG-PCL NPs and, FAM-AMO-21-HER-PEGPCL in SGC7901 and NUGC4 cells using ImageJ software. a IOD: integrated optical density. ${ }^{\text {b }}$ The SD value was for the mean IOD obtained from the three measurements

\begin{tabular}{lcc}
\hline Variable (IOD) $^{\mathrm{a}}$ & PEG-PCL NPs $^{\mathrm{b}}$ & HER-PEG-PCL NPs \\
\hline Rhodanmin-B (SGC7901) & $57821 \pm 564.3$ & $59061 \pm 1322.24$ \\
FAM (SGC7901) & $43253 \pm 741.7$ & $42165 \pm 1011.2$ \\
Rhodanmin-B (NUGC4) & $56949 \pm 759.2$ & $93181 \pm 956.7$ \\
FAM (NUGC4) & $42242 \pm 1017.5$ & $12463 \pm 1401.1$ \\
\hline
\end{tabular}

Table 5. Integrated optical density (IOD) of RhodanminB-PEG-PCL NPs and FAM-AMO-21-PEG-PCL NPs in SGC7901 and NUGC4 cells using ImageJ software. ${ }^{a}$ IOD: integrated optical density. ${ }^{\mathrm{b}}$ The SD value was for the mean IOD obtained from the three measurements

\begin{tabular}{lccc}
\hline Variable (IOD) $^{\mathrm{a}}$ & SGC7901 $^{\mathrm{b}}$ & NUGC4 $^{\mathrm{b}}$ & $\mathrm{p}$ \\
\hline Rhodanmin-B(PEG-PCLNPs) & $57821 \pm 564.3$ & $56949 \pm 759.2$ & $>0.05$ \\
FAM (HER-PCLNPs) & $43253 \pm 741.7$ & $42242 \pm 1017.5$ & $>0.05$ \\
\hline
\end{tabular}



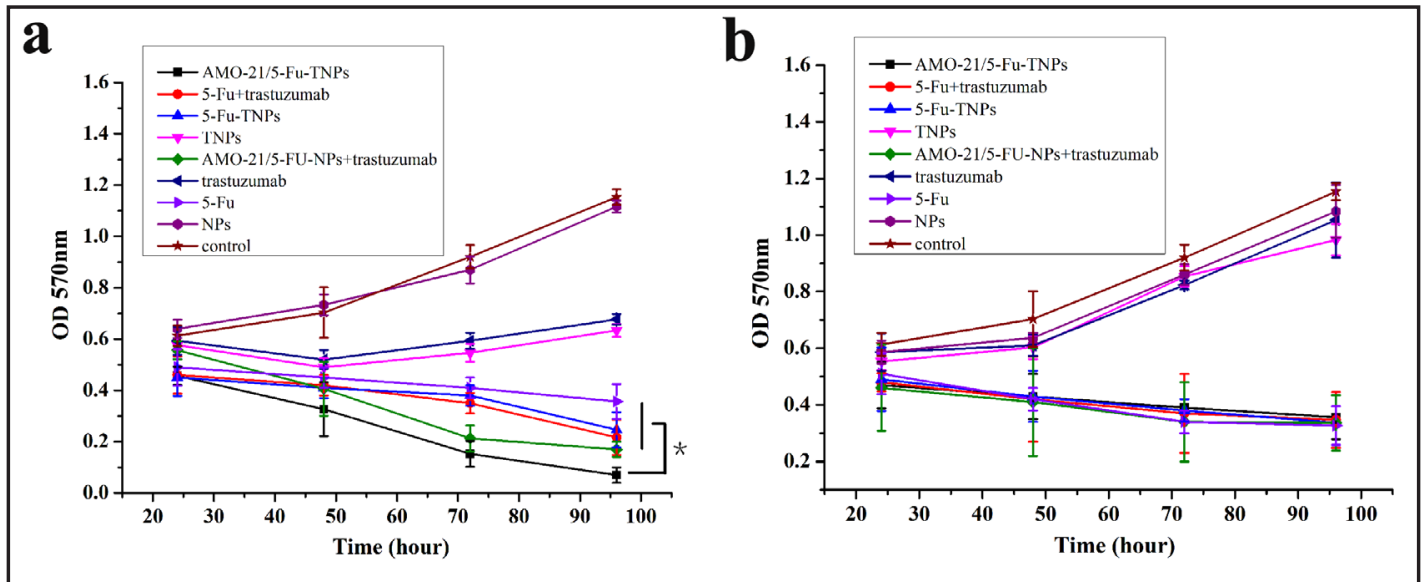

Fig. 6. Effect of blank NPs, blank TNPs (equal trastuzumab concentration), trastuzumab $(51 \mu \mathrm{g} / \mathrm{mL}), 5-\mathrm{Fu}$ $(5 \mu \mathrm{g} / \mathrm{mL}), 5-\mathrm{Fu}-\mathrm{TNPs}$ (equal 5-Fu and trastuzumab concentration), trastuzumab + 5-Fu, AMO-21 (100nmol/ L)/5-Fu-NPs (equal 5-Fu and trastuzumab concentration), AMO-21(100nmol/L)/5-Fu-TNPs (equal 5-Fu and trastuzumab concentration).on the growth of human NUGC4 (a) and SGC7901 cells (d). Cell growth was determined by MTT at every 24 hours for 4 days. Saline was used as treatment control. Cell viability was detected in both gastric cancer cells for every $24 \mathrm{~h}$ for $96 \mathrm{~h}$ after different treatments $\left({ }^{*} \mathrm{P}<0.05\right)(\mathrm{AMO}-21$, anti-miR-21 oligonucleotide; NPs, PEG-PCL nanoparticles; TNPs, HER-PEG-PCL nanoparticles).

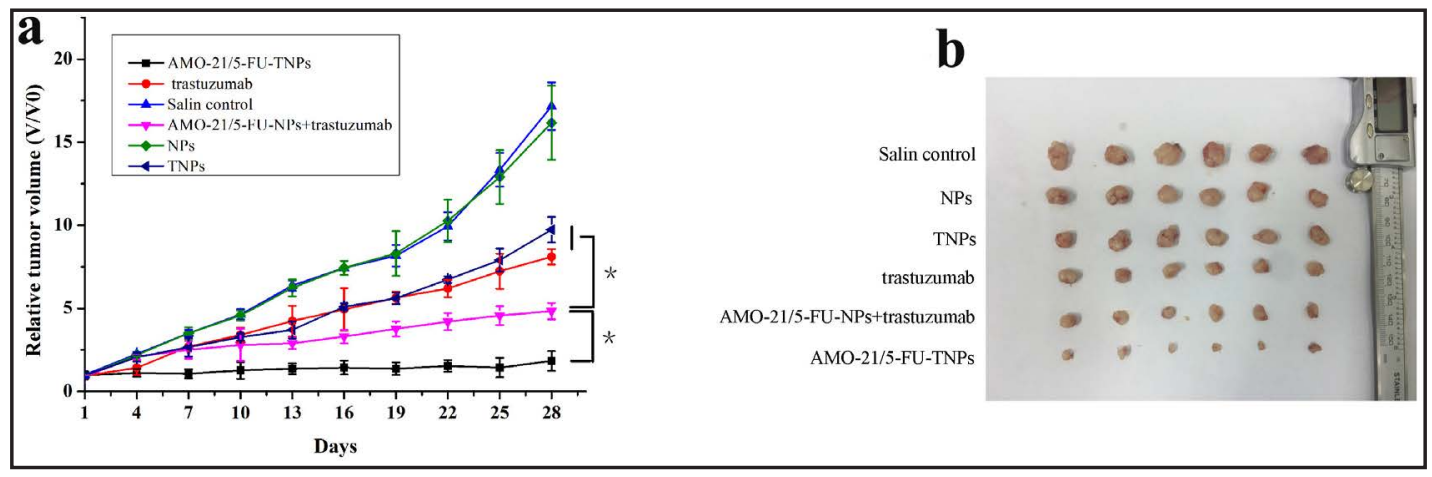

Fig. 7. Antitumor e fficacies of AMO-21/5-Fu for different treatments in human gastric cancer NUGC4 nude mice xenograft model. (a) Relative tumor volumes during treatment. (b)The tumor photographs of different groups after anticancer therapy. $\left({ }^{*} \mathrm{P}<0.05\right)$.

PCL was similar to HER-PEG-PCL in SGC7901 cells. However, the fluorescence intensity of HER-PEG-PCL was stronger than that of PEG-PCL in NUGC4, suggesting effective targeting of HER-PEG-PCL nanoparticles into NUGC4 cells.

\section{In vitro cytotoxicity}

The in vitro antitumor activity of the formulations were analyzed in NUGC4 and SGC7901 cells after treatment with saline control, blank NPs, blank TNPs (equal trastuzumab concentration), trastuzumab $(51 \mu \mathrm{g} / \mathrm{mL}), 5-\mathrm{Fu}(5 \mu \mathrm{g} / \mathrm{mL}), 5-\mathrm{Fu}-\mathrm{TNPs}$ (equal $5-\mathrm{Fu}$ and trastuzumab concentration), trastuzumab + 5-Fu, AMO-21 (100nmol/L) /5-FuNPs(equal 5-Fu and trastuzumab concentration), AMO-21(100nmol/L)/5-Fu-TNPs (equal 5-Fu and trastuzumab concentration) for 4 days using MTT assay. Cells treated with blank NPs exhibited maximum viability. It was similar to that of controls even after 4 days of incubation, suggesting absence of cytotoxicity (Fig. 6a, b). NUGC4 cells treated with TNPs showed similar levels of cytotoxicity to trastuzumab. These cells showed higher cytotoxicity when treated with AMO-21/5-Fu-TNPs compared with 5-Fu + trastuzumab and AMO-21/5$\mathrm{Fu}-\mathrm{NPs}+$ trastuzumab (Fig. 6a). In SGC7901 cells, the supression was not observed in the 


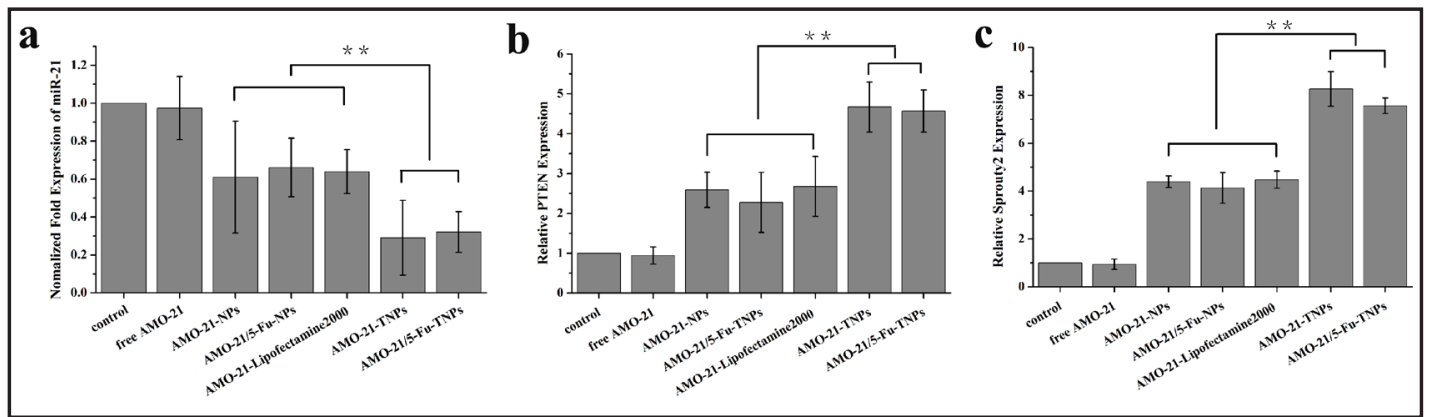

Fig. 8. Expression of miR-21 and its target genes Sprout2 and PTEN in NUGC4 cells after different treatments (from left to right, saline control, free AMO-21, AMO-21-NPs, AMO-21/5-Fu-NPs, AMO-21-Lipofectamine 2000, AMO-21-TNPs and AMO-21/5-Fu-TNPs) after $72 \mathrm{~h}$. The expression of miR-21 was normalized to U6 small nuclear RNA gene (U6 snRNA) control. The expression of Sprout2 and PTEN were normalized to betaactin. (a) Compared with the saline control, the expression of miR-21 in free AMO-21, AMO-21-NPs, AMO21/5-Fu-NPs, AMO-21-Lipofectamine 2000, AMO-21-TNPs and AMO-21/5-Fu-TNPs was 0.97-fold (P > 0.05), 2.5-fold, 2.2-fold, 2.6-fold, 4.6-fold and 4.5-fold.; (b) Compared with saline control, free AMO-21, AMO-21NPs, AMO-21/5-Fu-NPs, AMO-21-Lipofectamine 2000, AMO-21-TNPs and AMO-21/5-Fu-TNPs up-regulated PTEN expression by 0.9-fold ( $\mathrm{P}>0.05$ ), 2.6-fold, 2.73-fold, 2.7 -fold, 4.7-fold and 4.6-fold ( $\mathrm{P}<0.01)$. ${ }^{* *}, \mathrm{P}<0.01$ compared with AMO-21/5-Fu-NPs, AMO-21-Lipofectamine 2000 groups (c) Compared with saline control, free AMO-21, AMO-21-NPs, AMO-21/5-Fu-NPs AMO-21-Lipofectamine 2000, AMO-21-TNPs, AMO-21/5-FuTNPs up-regulated Sprouty2 expression by 1.1-fold (P > 0.05), 4.3-fold, 4.1-fold, 4.4-fold, 8.2-fold and 7.5fold $(\mathrm{P}<0.01)$. **, $\mathrm{P}<0.01$ compared with AMO-21/5-Fu-NPs, AMO-21-Lipofectamine 2000 groups. (AMO21,anti-miR-21 oligonucleotide; NPs, PEG-PCL nanoparticles; TNPs, HER-PEG-PCL nanoparticles).

groups of tratuzumab and TNPs. Besides, the cytotoxicity of 5-Fu, 5-Fu-TNPs, trastuzumab + 5-Fu, AMO-21/5-Fu-NPs, and AMO-21/5-Fu-TNPs were not significantly different $(\mathrm{P}>0.05)$ (Fig. 6b).

\section{In vivo antitumor activity of AMO-21/5-Fu-TNPS}

The in vivo antitumor efficacy of PTX-SF-NPs was evaluated on the human gastric cancer NUGC4 nude mice xenograft model (Fig. 7). In this study, blank NPs did not inhibit tumor growth. The tumors treated with TNPs and trastuzumab were significantly suppressed compared with those treated with saline $(\mathrm{P}<0.01)$, but the differences between TNPs and trastuzumab were not significant $(\mathrm{P}>0.05)$. The AMO-21-TNPs began to show an antitumor effect greater than that of trastuzumab after the first 7 days. The antitumor advantages of AM0-21/5-Fu-TNPs became more prominent as time passed ( $\mathrm{P}<0.05)$. AMO-21/5-Fu-TNPs completely halted tumor growth, and its antitumor effect was much higher than that of AMO$21 / 5-\mathrm{Fu}-\mathrm{NPs}+$ trastuzumab $(\mathrm{P}<0.05)$. The tumors in the group treated with AMO-21/5-FuTNPs were the smallest among all groups $(\mathrm{P}<0.05)$ (Fig. 7).

MiR-21 silencing, PTEN and Sprouty2 expression enhanced by AMO-21

It was investigated whether the encapsulated AMOs controlled the expression of target miRNAs and their downstream targets. Gastric cancer cells (NUGC4) were treated with AMO-21 containing TNPs and other controls (AMO-21-Lipofectamine 2000, AMO-21-NPs and AMO-21/5-Fu-NPs) for 48 hours. The expression of miR-21 and its target gene were assayed 48 hours after transfection using real time RT-PCR. As shown in Fig. 8a, the miR-21 expression in the positive control, treated with Lipofectamine 2000, was 60.9\% compared with that of the untreated cells. The miR-21 expression of AMO-21-NPs and AMO-21/5-FuNPs treated groups was similar (64.1\%, ). Notably, AMO-21-TNPs and AMO-21/5-Fu-TNPs treated groups exhibited the lower miR-21 expression than Lipofectamine 2000, AMO-21NPs and AMO-21/5-Fu-NPs. Since both PTEN and Sprouty2 are regulated by miR-21 [14, 15], the inhibition of miR-21 alters the PTEN and Sprouty2 expression. As shown in Fig. 
Hu et al.: Gastric Cancer Therapy

$8 b, c$, The up-regulation expression of PTEN and Sprouty2 in different groups were higher compare to control group. The up-regulation expression of PTEN and Sprouty 2 was similar in AMO-21-TNPs (4.6-fold, 8.2-fold) and AMO-21/5-Fu-TNPs (4.5-fold, 7.5-fold), both of which were higher than the group of AMO-21-Lipofectamine 2000 (2.6-fold, 4.4-fold, ${ }^{* *} P<$ $0.01)$, AMO-21-NPs (2.5-fold, 4.3-fold, $\left.{ }^{* *} P<0.01\right)$ groups and AMO-21/5-Fu-NPs $(2.2$-fold, 4.1 -fold, ${ }^{* *} P<0.01$ ) respectively. In contrast, no change in gene expression of free AMO-21 was found. In addition, the results indicated the superiority of TNP's over other transfection agents commercially available.

\section{Discussion}

In this research, a novel trastuzumab-conjugated nanoscale drug delivery vehicle was prepared, with distinct therapeutic mechanisms based on the antibody per se (e.g., ADCC, CDC) and the carrier drugs of AMO-21 and 5-Fu. Therapeutic applications of trastuzumab conjugated with nanoparticles encapsulated with AMO-21 and 5-Fu against GC cells was initially demonstrated. The nanoparticle-based antibody conjugates not only increased the efficiency of targeting and AMO-21 transfection efficiency, but also sensitized the cancer cells to trastuzumab and 5-Fu resulting in effective tumor suppression.

MiRs control key genes involved in cancer and drug resistance [39-42]. MiR-21 is a potential oncogenic miR involved in gastric cancer and is associated with trastuzumab and 5 -Fu resistance $[14,15]$. The miR overexpression is silenced by anti-miRs in a targeted manner [43]. AMO-21 was developed to specifically target miR-21. Traditional methods of oligonucleotide delivery are mediated via viruses and lipids such as Lipofectamine 2000 [44]. Modification of the oligonucleotide backbone also increases the stability of the miRs against enzymatic degradation and facilitates direct delivery to cells without the need for transfection. However, these methods are limited by their efficacy in vivo by serum nucleases, lysosomal degradation, and non-specific absorption [20].

A nanoparticle-based delivery system improves stability and delivery efficiency. NPsbased delivery may be via active or passive targeting [45]. Passive targeting is facilitated by EPR or via localized application and delivery. Active targeting is accomplished by conjugating different targeting moieties with the surface of NPs [46]. Antibodies represent ideal anticancer agents. They have been the focus of intense research activity since the production of customized monoclonal antibody in the mid-1970s. However, antibodies have been used successfully as immunotargeting agents [47]. The strategy of this research employed tumor-cell-specific NPs conjugated with antibodies such as trastuzumab with the NP surface. It was previously reported that effective delivery of docetaxel and miRNA using PEG-PCL-based nanoparticles. PEG-PCL-based nanosystems targeted cancer cells and enhanced the cytotoxicity of docetaxel by sequence-specific gene silencing [26]. The current study developed nanoparticles of copolymers PEG-PCL conjugated with trastuzumab for targeted delivery of AMO-21. HER-PEG-PCL NPs were prepared using one-step carbodiimide coupling using EDAc and Sulfo-NHS in aqueous phase. Covalent coupling of amino groups at the surface of PEG-PCL with the carboxyl groups of trastuzumab was analyzed by XPS (Fig. 4a). The formulation with the highest surface density of the ligand was further evaluated for the delivery of AM0-21 into GC cells. A herceptin-to-PEG-PCL mass ratio of 1:1 favored efficient conjugation (Table 2). The free amino groups on the NPs surface provide linkers for the ligand molecules in the presence of EDAc. The increase in the number of amino groups in the PEG-PCL molecules increased the efficiency of covalent coupling. At a 50\% ratio of PEGPCL-to-trastuzumab, the binding efficiency was the highest. The NPs generated by doubleemulsion solvent evaporation method measured approximately $200 \mathrm{~nm}$ in size (Fig. 4b and Table 3), with a negetive zeta potential conducive to cellular uptake via endocytosis [38]. A sustained release of AMO-21 in vitro suggests diffusion from the polymeric matrix of NPs for effective gene silencing (Fig. 4c ). Meanwhile, the 5-FU release study also demonstrated a burst release be-havior following controlled-release ( Fig. 4c); Cytotoxic profiles were 
similar for 5-FU + trastuzumab and single drug-loaded NPs (5-Fu-TNPs), suggesting that the triggering mechanism for the release of the drug from the NPs into the cytosols was highly efficient. Therefore, the data of this study confirm that TNP encapsulation not only aids in the stabilization of AMO-21 in the culture condition, which sustains its down-regulating effect, but also increases the efficiency co-administered with conventional chemotherapeutic drugs

Nonspecific interaction between nanocarriers and non-target cells is a critical challenge that limits the therapeutic efficacy resulting in adverse effects [48]. The intracellular uptake of AMOs was monitored by the means of fluorescently-labeled AMO-21 and FAM-AMO-21 (green) encapsulated rhodamine B (red)-labeled HER-PEG-PCL NPs under fluorescence microscopy. FAM-AMO-21 was visualized in the cytoplasm of GC cells after transfection. Compared with PGE-PCL, the HER2 targeting ligand in the formulation contributed to improved cellular uptake, and enhanced transfection efficiency of NUGC4 cells (Fig. 5b), via recognition of overexpressed surface antigens. Furthermore, the targeted uptake using HER2-negative cell line SGC7901 was established as a control. It was found that the cellular uptake of HER-PEG-PCL and PEG-PCL NPs was similar (Fig. 5a). The reduced uptake level of FAM-AMO-21-TNPs in SGC7901 cells than in NUGC4 cells further confirmed that the entry of TNPs into GC cells was mediated by trastuzumab antibody-mediated endocytosis (Fig. $5 \mathrm{a}, \mathrm{b})$. The cellular effect of the nanoformulation containing trastuzumab conjugated with nanocarriers was enhanced by active entry into cancer cells expressing HER2.

Trastuzumab conjugated with PEG-PCL NPs showed cytotoxic effects similar to free trastuzumab against NUGC4, which suggests that the antibody activity was retained even after nanoparticle synthesis. The AMO-21/5-Fu-TNPs showed a higher level of cytotoxicity compared with 5-Fu + trastuzumab (Fig. 6a). These results indicate that AMO-21-TNPs penetrate the cells and release AMO-21. These results indicated that AMO-21 could act as a sensitizer of trastuzumab and 5-Fu when it was entrapped in TNPs, suggesting that the enhanced cytotoxicity of AMO-21/5-Fu-TNP in NUGC4 cells was mediated via targeted delivery. The cellular interaction and increased transfection efficiency significantly downregulate miR-21 expression compared with PEG-PCL NPs and Lipofectamine 2000 in NUGC4 cells, as demonstrated by RT-PCR. The expression of PTEN and Sprouty2 are increased continuously and the AM0-21/5-Fu-TNPs suppression of NUGC4 cell proliferation and growth is enhanced consistent with previous studies in GC cells with high miR-21 expression restoring sensitivity to trastuzumab and 5-Fu [14, 15]_ENREF_13. Therefore, trastuzumab acts as a targeting ligand to improve the transfection rate of AMO-21 in NUGC4 cells. Furthermore, TNPs treatment showed no cytotoxicity toward SGC7901 cells (Fig. 6b), which showed a potential for reduced systemic toxicity while retaining efficacy against target cells. The efficacy of trastuzumab-conjugated NPs was higher and more direct compared with PEG-PCL NPs alone for HER2-positive cells, with less cytotoxicity for HER2-negitive cells. Therefore, increased anti-tumor effect in HER2-positive GC cells decreases the incidence of side effects. In vivo study, AM0-21/5-Fu-TNPs completely halted tumor growth, and its antitumor effect was much higher than other groups.

Compared with a commercial transfection agent lipofectamine 2000 and PEG-PCL NPs, the TNP encapsulating AMO-21 led to the efficient inhibition of miR-21 and an increase in PTEN and Sprouty2 expression in NUGC4 cells, while the treatment of free AMO-21, resulted in negligible change (Fig. 8a,b).This suggests that the inhibition of miR-21 and subsequent increment in target genes can be attributed to the antagonism of miR-21 with AM0-21.

Reports investigating targeted PEG-PCL-based delivery combined with ligands for anti-miR delivery to GC are rare. In this study, it was reported that the synthesis of PEG-PCL NPs targeting HER2 for the delivery of AMO-21 and 5-Fu to GC cells. The TNPs showed favorable physicochemical properties and selective uptake by targeted cells. TNPs containing AM0-21 significantly enhanced target genes that are known to be repressed by miR-21. These findings suggest the potential application of anti-miR therapies in GC. These studies represent the initial step in AMO-21 and nanotechnology-based therapies against gastric cancer. In addition, the potential role of HER-PEG-PCL NPs to transfect AMOs, as well as therapeutic antibodies into cancer cells facilitates a multi-pronged strategy against

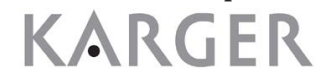




\section{Cellular Physiology Cell Physiol Biochem 2017;44:2158-2173

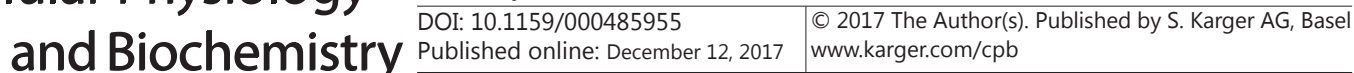 \\ Hu et al.: Gastric Cancer Therapy}

trastuzumab-resistant tumors. The efficacy of AMO-21 TNPs in targeting gastric tumors will be investigated in future studies.

\section{Conclusion}

We report the anticancer potential of a combination of 5-Fu treatment and AMO-21 technology using trastuzumab conjugated PEG-PCL copolymers, an available co-carrier of chemotherapeutant and AMO-21, could effectively deliver 5-FU and AMO-21 simultaneously, this trastuzumab-conjuctated nanoparticles effectively protected AMO-21 against nuclease degradation and suppressed the target miRNA expression in NUGC4 GC (HER2-expressing) cells and further up-regulated phosphatase and tensin homolog (PTEN) and Sprayt2. As a result, the sensitivity of GC cells to trastuzumab and 5-Fu was enhanced. The approach enhances the targeting by trastuzumab as well as antibody-dependent cellular cytotoxicity (ADCC) of immune effector cells. The co-delivery AMO-21 significantly improved the cytotoxicity of $5-\mathrm{Fu}$ and trastuzumab to NUGC4 cells. Our results provide invaluable information regarding the future application of drug-polymer complexes combined with gene therapy for cancer treatments. Taken together, our findings suggest that the co-delivery of 5-Fu treatment and AMO-21 by HER-PEG-PCL nanoparticle might be a potential clinical strategy for gastric cancer chemotherapy.

\section{Disclosure Statement}

The authors declare that they have no conflict interests.

\section{Acknowledgements}

This work was supported by National Natural Science Foundation of China (Nos. 81401968, 81602077, 81472216, 81302053, 81602065, 81502069, 81672398), National Postdoctoral Foundation of China (2016M601760), Postdoctoral Foundation of Jiangsu Province (1601089C), Jiangsu Provincial Natural Science Foundation (BK20141245), The Eleventh Group of Six Talent Peak Project in Jiangsu Province (2014-WSN-073), Lianyungang Science and Technology Development Project (SH1614), The Fifth Period 333 Project of Jiangsu Province (BRA2016300).

\section{References}

$>1$ Chen W, Zheng R, Baade PD, Zhang S, Zeng H, Bray F, Jemal A, Yu XQ He J: Cancer statistics in China, 2015CA Cancer J Clin 2016;66:115-132.

2 Power DG, Kelsen DP, Shah MA: Advanced gastric cancer--slow but steady progress. Cancer Treat Rev 2010;36:384-392.

3 Takashima A, Boku N, Kato K, Nakamura K, Mizusawa J, Fukuda H, Shirao K, Shimada Y, Ohtsu A: Survival prolongation after treatment failure of first-line chemotherapy in patients with advanced gastric cancer: combined analysis of the Japan Clinical Oncology group trials JCOG9205 and JCOG9912. Gastric Cancer 2014;17:522-528.

4 Gravalos C, Jimeno A: HER2 in gastric cancer: a new prognostic factor and a novel therapeutic target. Ann Oncol 2008;19:1523-1529.

-5 Hofmann M, Stoss O, Shi D, Buttner R, van de Vijver M, Kim W, Ochiai A, Ruschoff J, Henkel T: Assessment of a HER2 scoring system for gastric cancer: results from a validation study. Histopathology 2008;52:797-805.

6 Tanner M, Hollmen M, Junttila TT, Kapanen AI, Tommola S, Soini Y, Helin H, Salo J, Joensuu H, Sihvo E, Elenius K, Isola J: Amplification of HER-2 in gastric carcinoma: association with Topoisomerase IIalpha gene amplification, intestinal type, poor prognosis and sensitivity to trastuzumab. Ann Oncol 2005;16:273278. 


\section{Cellular Physiology Cell Physiol Biochem 2017;44:2158-2173

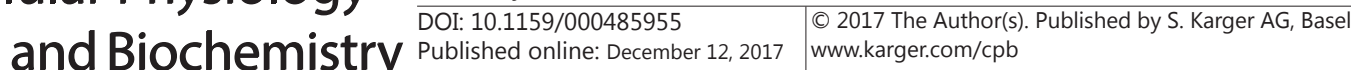

Hu et al.: Gastric Cancer Therapy

7 Bang YJ, Van Cutsem E, Feyereislova A, Chung HC, Shen L, Sawaki A, Lordick F, Ohtsu A, Omuro Y, Satoh T, Aprile G, Kulikov E, Hill J, Lehle M, Ruschoff J, Kang YK: Trastuzumab in combination with chemotherapy versus chemotherapy alone for treatment of HER2-positive advanced gastric or gastro-oesophageal junction cancer (ToGA): a phase 3, open-label, randomised controlled trial. Lancet 2010;376:687-697.

-8 Yin M, Yuan Y, Cui Y, Hong X, Luo H, Hu X, Tang M, Hescheler J, Xi J: Puerarin Suppresses the Self-Renewal of Murine Embryonic Stem Cells by Inhibition of REST-MiR-21 Regulatory Pathway. Cell Physiol Biochem 2015;37:527-536.

-9 Calin GA, Croce CM: MicroRNA signatures in human cancers. Nat Rev Cancer 2006;6:857-866.

$\checkmark 10$ Kasinski AL, Slack FJ: Epigenetics and genetics. MicroRNAs en route to the clinic: progress in validating and targeting microRNAs for cancer therapy. Nat Rev Cancer 2011;11:849-864.

-11 Li Z, Rana TM: Therapeutic targeting of microRNAs: current status and future challenges. Nat Rev Drug Disco 2014;13:622-638.

12 Deng Y, Huang Z, Xu Y, Jin J, Zhuo W, Zhang C, Zhang X, Shen M, Yan X, Wang L: MiR-215 modulates gastric cancer cell proliferation by targeting RB1. Cancer Lett 2014;342:27-35.

13 Ma L, Reinhardt F, Pan E, Soutschek J, Bhat B, Marcusson EG, Teruya-Feldstein J, Bell GW, Weinberg RA: Therapeutic silencing of miR-10b inhibits metastasis in a mouse mammary tumor model. Nat Biotechnol 2010;28:341-347.

14 Eto K, Iwatsuki M, Watanabe M, Ida S, Ishimoto T, Iwagami S, Baba Y, Sakamoto Y, Miyamoto Y, Yoshida $\mathrm{N}$ : The microRNA-21/PTEN pathway regulates the sensitivity of HER2-positive gastric cancer cells to trastuzumab. Ann Surg Oncol 2014;21:343-350.

15 Feng YH, Wu CL, Shiau AL, Lee JC, Chang JG, Lu PJ, Tung CL, Feng LY, Huang WT, Tsao CJ: MicroRNA-21mediated regulation of Sprouty2 protein expression enhances the cytotoxic effect of 5 -fluorouracil and metformin in colon cancer cells. Int J Mol Med 2012;29:920-926.

-16 Weiler J, Hunziker J, Hall J: Anti-miRNA oligonucleotides (AMOs): ammunition to target miRNAs implicated in human disease? Gene Ther 2006;13:496-502.

17 Lennox KA, Owczarzy R, Thomas DM, Walder JA, Behlke MA: Improved Performance of Anti-miRNA Oligonucleotides Using a Novel Non-Nucleotide Modifier. Mol Ther Nucleic Acids 2013;2:e117.

18 Ge X, Zhang Q Cai Y, Duan S, Chen S, Lv N, Jin T, Chen Y, Yuan W: PEG-PCL-DEX polymersome-protamine vector as an efficient gene delivery system via PEG-guided self-assembly. Nanomedicine (Lond) 2014;9:1193-1207.

19 Shukla GC, Haque F, Tor Y, Wilhelmsson LM, Toulme JJ, Isambert H, Guo P, Rossi JJ, Tenenbaum SA, Shapiro BA: A boost for the emerging field of RNA nanotechnology. ACS Nano 2011;5:3405-3418.

20 Zhang M, Zhou X, Wang B, Yung BC, Lee LJ, Ghoshal K, Lee RJ: Lactosylated gramicidin-based lipid nanoparticles (Lac-GLN) for targeted delivery of anti-miR-155 to hepatocellular carcinoma. J Control Release 2013;168:251-261.

-21 Hatakeyama H, Murata M, Sato Y, Takahashi M, Minakawa N, Matsuda A, Harashima H: The systemic administration of an anti-miRNA oligonucleotide encapsulated $\mathrm{pH}$-sensitive liposome results in reduced level of hepatic microRNA-122 in mice. J Control Release 2014;173:43-50.

-22 Lee H, Lytton-Jean AK, Chen Y, Love KT, Park AI, Karagiannis ED, Sehgal A, Querbes W, Zurenko CS, Jayaraman M, Peng CG, Charisse K, Borodovsky A, Manoharan M, Donahoe JS, Truelove J, Nahrendorf M, Langer R, Anderson DG: Molecularly self-assembled nucleic acid nanoparticles for targeted in vivo siRNA delivery. Nat Nanotechnol 2012;7:389-393.

-23 Liu Y, Li K, Liu B, Feng S-S: A strategy for precision engineering of nanoparticles of biodegradable copolymers for quantitative control of targeted drug delivery. Biomaterials 2010;31:9145-9155.

24 Haun JB, Devaraj NK, Hilderbrand SA, Lee H, Weissleder R: Bioorthogonal chemistry amplifies nanoparticle binding and enhances the sensitivity of cell detection. Nat Nanotechnol 2010;5:660-665.

25 Li R, Li X, Xie L, Ding D, Hu Y, Qian X, Yu L, Ding Y, Jiang X, Liu B: Preparation and evaluation of PEG-PCL nanoparticles for local tetradrine delivery. Int J Pharm 2009;379:158-166.

26 Liu Q, Li RT, Qian HQ, Wei J, Xie L, Shen J, Yang M, Qian XP, Yu LX, Jiang XQ Liu BR: Targeted delivery of miR-200c/DOC to inhibit cancer stem cells and cancer cells by the gelatinases-stimuli nanoparticles. Biomaterials 2013;34:7191-7203.

27 Wu FL, Li RT, Yang M, Yue GF, Wang HY, Liu Q, Cui FB, Wu PY, Ding H, Yu LX, Qian XP, Liu BR: Gelatinasesstimuli nanoparticles encapsulating 5-fluorouridine and 5-aza-2'-deoxycytidine enhance the sensitivity of gastric cancer cells to chemical therapeutics. Cancer Lett 2015;363:7-16. 


\section{Cellular Physiology Cell Physiol Biochem 2017;44:2158-2173

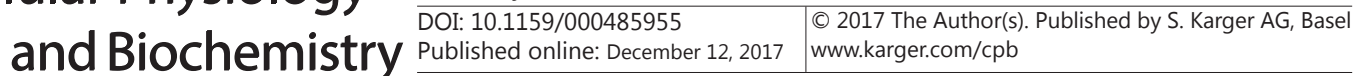

Hu et al.: Gastric Cancer Therapy

-28 Arya G, Vandana M, Acharya S, Sahoo SK: Enhanced antiproliferative activity of Herceptin (HER2)conjugated gemcitabine-loaded chitosan nanoparticle in pancreatic cancer therapy. Nanomedicine 2011;7:859-870.

29 Zhang Z, Wang J, Ji D, Wang C, Liu R, Wu Z, Liu L, Zhu D, Chang J, Geng R, Xiong L, Fang Q Li J: Functional genetic approach identifies MET, HER3, IGF1R, INSR pathways as determinants of lapatinib unresponsiveness in HER2-positive gastric cancer. Clin Cancer Res 2014;20:4559-4573.

30 Cui Y, Li SB, Peng XC, Wu J, Fu GH: Trastuzumab Inhibits Growth of HER2-Negative Gastric Cancer Cells Through Gastrin-Initialized CCKBR Signaling. Dig Dis Sci 2015;60:3631-3641.

-31 Liu Q, Li RT, Qian HQ, Yang M, Zhu ZS, Wu W, Qian XP, Yu LX, Jiang XQ, Liu BR: Gelatinase-stimuli strategy enhances the tumor delivery and therapeutic efficacy of docetaxel-loaded poly(ethylene glycol)poly(varepsilon-caprolactone) nanoparticles. Int J Nanomedicine 2012;7:281-295.

-32 Wu P, Liu Q Li R, Wang J, Zhen X, Yue G, Wang H, Cui F, Wu F, Yang M, Qian X, Yu L, Jiang X, Liu B: Facile preparation of paclitaxel loaded silk fibroin nanoparticles for enhanced antitumor efficacy by locoregional drug delivery. ACS Appl Mater Interfaces 2013;5:12638-12645.

33 Shi SJ, Zhong ZR, Liu J, Zhang ZR, Sun X, Gong T: Solid lipid nanoparticles loaded with anti-microRNA oligonucleotides (AMOs) for suppression of microRNA-21 functions in human lung cancer cells. Pharm Res 2012;29:97-109.

34 Wang F, Li T, Zhang B, Li H, Wu Q Yang L, Nie Y, Wu K, Shi Y, Fan D: MicroRNA-19a/b regulates multidrug resistance in human gastric cancer cells by targeting PTEN. Biochem Biophys Res Commun 2013;434:688694.

-35 Peier M, Walpen T, Christofori G, Battegay E, Humar R: Sprouty2 expression controls endothelial monolayer integrity and quiescence. Angiogenesis 2013;16:455-468.

-36 Livak KJ, Schmittgen TD: Analysis of relative gene expression data using real-time quantitative PCR and the 2- $\Delta \Delta$ CT method. Methods 2001;25:402-408.

-37 Liu Y, Li K, Liu B, Feng SS: A strategy for precision engineering of nanoparticles of biodegradable copolymers for quantitative control of targeted drug delivery. Biomaterials 2010;31:9145-9155.

-38 Iyer AK, Khaled G, Fang J, Maeda H: Exploiting the enhanced permeability and retention effect for tumor targeting. Drug Discov Today 2006;11:812-818.

-39 Croce CM: Causes and consequences of microRNA dysregulation in cancer. Nat Rev Genet 2009;10:704-714.

40 Lin L, Tu HB, Wu L, Liu M, Jiang GN: MicroRNA-21 Regulates Non-Small Cell Lung Cancer Cell Invasion and Chemo-Sensitivity through SMAD7. Cell Physiol Biochem 2016;38:2152-2162.

41 Wang D, Fan Z, Liu F, Zuo J: Hsa-miR-21 and Hsa-miR-29 in Tissue as Potential Diagnostic and Prognostic Biomarkers for Gastric Cancer. Cell Physiol Biochem 2015;37:1454-1462.

42 Song W, Li Q, Wang L: Modulation of FoxO1 expression by miR-21 to promote growth of pancreatic ductal adenocarcinoma. Cell Physiol Biochem 2015;35:184-190.

43 Li S, Fan Q, He S, Tang T, Liao Y, Xie J: MicroRNA-21 negatively regulates Treg cells through a TGF-beta1/ Smad-independent pathway in patients with coronary heart disease. Cell Physiol Biochem 2015;37:866878.

44 Cheng M, Wu G, Song Y, Wang L, Tu L, Zhang L, Zhang C: Celastrol-Induced Suppression of the MiR-21/ERK Signalling Pathway Attenuates Cardiac Fibrosis and Dysfunction. Cell Physiol Biochem 2016;38:1928-1938.

45 Das M, Mohanty C, Sahoo SK: Ligand-based targeted therapy for cancer tissue. Expert Opin Drug Deliv 2009;6:285-304.

46 Maeda H, Wu J, Sawa T, Matsumura Y, Hori K: Tumor vascular permeability and the EPR effect in macromolecular therapeutics: a review. J Control Release 2000;65:271-284.

47 Cirstoiu-Hapca A, Buchegger F, Lange N, Bossy L, Gurny R, Delie F: Benefit of anti-HER2-coated paclitaxelloaded immuno-nanoparticles in the treatment of disseminated ovarian cancer: Therapeutic efficacy and biodistribution in mice. J Control Release 2010;144:324-331.

48 Whitehead KA, Langer R, Anderson DG: Knocking down barriers: advances in siRNA delivery. Nat Rev Drug Discov 2009;8:129-138. 